\title{
Inflammation, Immune System and Alzheimer’s disease: A Review of the Findings from the Major GWAS Studies
}

\author{
Christiane Reitz ${ }^{1,2,3 *}$ and Giuseppe Tosto ${ }^{1,2,3}$
}

${ }^{1}$ The Taub Institute for Research on Alzheimer's Disease and the Aging Brain, Columbia University, New York, New York, USA

${ }^{2}$ The Gertrude H. Sergievsky Center, Columbia University, New York, New York, USA

${ }^{3}$ The Department of Neurology, Columbia University, New York, New York, USA

\begin{abstract}
A role for inflammation in the pathogenesis of Alzheimer's disease (AD) has been a matter of debate since the beginning of $A D$ research in 1907. Over the past three decades immunohistochemical studies demonstrated that amyloid plaques are co-localized with activated microgliaas well as a broad spectrum of inflammation-related proteins (complement factors, acute-phase proteins, pro-inflammatory cytokines) spurring the hypothesis that amyloid plaques may benests of a non-immune mediated inflammatory reactions induced by fibrillar $A \beta$ deposits. However, molecular studies also suggest that inflammation-related proteins are involved in $A \beta$ generation and clearance, gliosis and increased phosphorylation of tau with accelerated tangle formation, i.e. several events considered key pathogenic steps in $A D$. In line with both notions, neuropathological studies show a close relation between fibrillar $A \beta$ deposits, inflammation and neuroregeneration in relatively early stages preceding extensive tau-related neurofibrillary changes. Genetic studies address the issue of reverse causation and thus can help clarify the temporal relation between inflammatory changes and AD. In this review article we summarize the findings on inflammatory genes from the large scale genetic studies in $A D$ and discuss directions for future research.
\end{abstract}

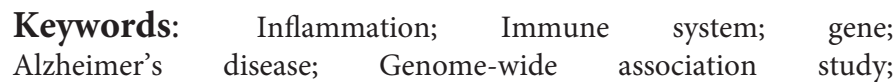
Sequencing

\section{Introduction}

A role for inflammation in the pathogenesis of Alzheimer's disease $(\mathrm{AD})$ has been a matter of debatesince the beginning of $\mathrm{AD}$ research. In 1910, although lacking the tools to pursue this hypothesis experimentally, Oskar Fischer suggested that senile plaques form as the result of an extracellular deposition of an abnormal substance in the cortex. He proposed that accumulation of this substance induces a local inflammatory reaction followed by an attempted but doomed regenerative response of the surrounding nerve fibers. Seven decades later, the presence of complement factors and activated microglia in plaques has been demonstrated using monoclonal antibodies stipulating the notion that $\mathrm{A} \beta$ itself can stimulate a local inflammatory response [1]. This views supported by in vitro studies showing that fibrillar $A \beta$ can bind complement factor $\mathrm{C} 1$ and activate the classical complement pathway in an antibody-independent fashion [2]. Such activated early complement factors could play an important role in the local recruitment and activation of microglial cells expressing the complement receptors CR3 and CR4 [3]. A $\beta$ activates microglia by binding to the receptor for advanced glycation end products (RAGE) [4] as well as other scavenger receptors [5]. In addition, the LPS receptor, CD14, interacts with fibrillar $A \beta[6]$ and microglia destroys $A \beta_{1-42}$ damaged neurons by a CD14 dependent process [7]. Fibrillar $A \beta$ has been shown to increase cytokine and nitric oxide production in microglia dependent on CD14, TLR2 and TLR4 [8]. A $\beta$ also triggers inflammatory signaling through heterodimer formation of Toll-like receptor 4 and 6 [9]. However, molecular studies also suggest that inflammation-related proteins are involved in several events considered key pathogenic steps in AD [10]. Chronic inflammation and cytokine up-regulation induce tau hyperphosphorylation in prepathological 3xTg-AD mice [11]. In addition, studies [12-14] indicate that inflammatory processes are involved in clearing or degrading $A \beta$ depositions. The deficiency of CCR2, a chemokine receptor, impairs microglia accumulation and increases $\mathrm{A} \beta$ deposition in amyloid precursor protein (APP)-transgenic mice, indicating a role for microglia in regulating $A \beta$ accumulation $[15,16]$. On the other hand, chronic lipopolysaccharide (LPS)-induced neuroinflammation increases intraneuronal $A \beta$ load in transgenic mice, [17] possibly through the release of proinflammatory cytokines and other toxic speciesand the subsequent exacerbation of AD-related pathological features.

Based on these findings, inflammation could be both cause or consequence of the disease process. Clinicopathological studies show that the presence of activated microglia and inflammation-related mediators in the cerebral neocortex of patients with a low Break stage for $\mathrm{AD}$ pathology precedes extensive tau-related neurofibrillary pathology [18]. Studies using positron emission tomography (PET) with the peripheral benzodiazepine receptor ligand PK-11195 as a marker for activated microglia indicate that activation of microglia occurs before cerebral atrophy in AD patients [19]. In line with this notion of an early involvement of inflammation and immune response in the disease etiology, aPET study using the Pittsburg compound B (PIB) for visualization of fibrillar amyloid and the PK-11195 ligand for microglia activation detected amyloid deposition with microglia activation in $\sim 50 \%$ of patients with mild cognitive impairment [20]. Of note, there is evidence that brain $A \beta$ loadas measured by PIB labeling is correlated with peripheral acetylcholinesterase (AChE) levels [21]. Elevated AChE levels, in turn, are prevalent in $\mathrm{AD}$ and lead to the commonly seen decreased acetylcholine levels. The fact that

*Corresponding author: Christiane Reitz, Gertrude H. Sergievsky Center, 630 West 168th Street, Columbia University, New York, NY 10032, USA, Tel: 212-305 0865; Fax: 212-305-2518; E-mail: cr2101@columbia.edu

Received July 06, 2013; Accepted July 22, 2013; Published July 25, 2013

Citation: Reitz C, Tosto G (2013) Inflammation, Immune System and Alzheimer's disease: A Review of the Findings from the Major GWAS Studies. J Mol Genet Med 7: 60. doi:10.4172/1747-0862.1000060

Copyright: (c) 2013 Reitz C, et al. This is an open-access article distributed under the terms of the Creative Commons Attribution License, which permits unrestricted use, distribution, and reproduction in any medium, provided the original author and source are credited 
acetylcholine blocks inflammatory mechanisms suggests that $\mathrm{ACH}$ inhibitors, which constitute four out of the five drugs approved for treatment, may also be beneficial through an effect on this this pathway. In summary, it is likely that some components of the molecularly and cellularly inflammation pathway are promoting pathological processes leading to $\mathrm{AD}$, whereas other components serve to do the opposite (in more detail reviewed in $[22,23])$.

Through Mendelian randomization, genetic studies address the issue of reverse causation and thus can help clarify the causal and temporal relation between inflammatory changes/immune response and $\mathrm{AD}$. In this review article we summarize findings on inflammatory genes from large scale genetic studies in $\mathrm{AD}$ and discuss directions for future research.

\section{Findings from Genetic Studies}

In the beginning of the century, thousands of candidate-gene-based association studies aiming to identify susceptibility loci for late-onset $\mathrm{AD}$ were performed but only one gene, the sortilin-related receptor (SORL1) which is implicated in intracellular trafficking of APP, could be consistently replicated in independent datasets and implicated in the disease. The main reasons for these inconsistencies between studies are sample heterogeneity with differences in linkage disequilibrium (LD) patterns and allele frequencies, and small sample sizes leading to limited power to detect small or moderate effect sizes. In the past five years, technological advances in high-throughput genome-wide arrays allowed the hypothesis-free simultaneous examination of thousands to millions of polymorphisms across the genome.Large collaborative efforts capitalizing on this technology have significantly advanced the knowledge on the genetic underpinnings of late-onset Alzheimer's disease (LOAD) and pathways involved by identifying several novel risk loci. Of note, besides genes clearly clustering in the lipid metabolism, intracellular trafficking and APP metabolism pathways, several of the identified genes cluster in the inflammation/immune response pathway.

Most genome-wide association studies (GWAS) contributing to this gained knowledge were performed in non-Hispanic Whites of European ancestry. The first set of studies identified four genes (CLU, PICALM, CR1 and BIN1) as AD susceptibility loci [24-26]. While CLU, also known as a polipoprotein $\mathrm{J}$ (ApoJ), is similar to APOE involved in lipid transport [27] and is also hypothesized to act as an extracellular chaperone that influences $A \beta$-aggregation and receptor-mediated A $\beta$ clearance by endocytosis [28], and BIN1 [29] and PICALM [30] are involved in clathrin-mediated endocytosis, CR1 is a cell-surface receptor that is part of the complement system.It has binding sites for complement factors $\mathrm{C} 3 \mathrm{~b}$ and $\mathrm{C} 4 \mathrm{~b}$ and is involved in clearing immunecomplexes containing these two proteins. Since $A \beta$ oligomers can bind $\mathrm{C} 3 \mathrm{~b}$ as described above, $\mathrm{CR} 1$ may participate in the clearance of $\mathrm{A} \beta$ and play a role in neuroinflammation in $\mathrm{AD}$ [31]. Interestingly, Clu may play a role in this process as an inhibitor [32].

The second set of large GWA studies identified five additional susceptibility genes (CD33, MS4A4A/MS4A4E/MS4A6E cluster, $A B C A 7, C D 2 A P$ and EPHA1 [33,34] out of which all are likely involved in the immune system (Table 1). The CD33 gene encodes a protein that is a member of a family of cell surface immune receptors that bind extracellular sialylatedglycans and signal via a cytoplasmic domain called the immune receptor tyrosine inhibitory motif [33,34]. CD33 has primarily been studied in the peripheral immune system where it is expressed on myeloid progenitors and monocytes and also in the brain.

\begin{tabular}{|l|c|c|c|}
\hline Gene & Chr & Position & Disease-associated SNP \\
\hline CR1 & 1 & 207692049 & rs6656401 \\
\hline CD2AP & 6 & 47487762 & rs10948363 \\
\hline EPHA1 & 7 & 143110762 & rs11771145 \\
\hline CLU & 8 & 27467686 & rs9331896 \\
\hline MS4A6A & 11 & 59923508 & rs983392 \\
\hline ABCA7 & 19 & 1063443 & rs4147929 \\
\hline CD33 & 19 & 51727962 & rs3865444 \\
\hline TREM2 & 6 & 41129252 & rs75932628 \\
\hline
\end{tabular}

Table 1: Inflammatory pathway genes associated with Alzheimer's disease.

In the periphery, CD33 appears to inhibit proliferation of myeloid cells [35]. The MS4A4A/MS4A4E/MS4A6E locus is part of a cluster of 15 $M S 4 A$ genes on chromosome 11 and encodes proteins with multiple membrane-spanning domains that were initially identified by their homology to CD20, a B-lymphocyte cell surface molecule. Little is known about the function of MS4A4A gene products; however, like CD33, MS4A4A is expressed on myeloid cells and monocytes and likely has an immune-related function. EPHA1 encodes a member of the ephrin family of cell surface receptors which interact with ephrin ligands on adjacent cells to modulate cell adhesion, migration, and axon guidance and synapse formation and plasticity. While there is a substantial body of research on the function of ephrin receptors in general, little is known about the EPHA1 gene product. Like other ephrin receptors, it regulates cell morphology and motility [36] and early work implicated this receptor in regulating vascular morphogenesis and angiogenesis [37]. EPHA1 knockout in mouse results in abnormal tail and reproductive tract development, [38] but no effects on the brain. Consistent with this notion, in mouse, expression is restricted to epithelial tissue. In humans, EPHA1 is expressed by CD4positive T- lymphocytes [39], monocytes, [40] intestinal epithelium, and colon. Combined with the lack of evidence for brain expression this may suggest that, like CD33, CR1, and MS4A4/MS4A6E, the role of the EPHAlgene product in $\mathrm{AD}$ may be mediated though the immune system. The $\mathrm{CD} 2$ associated protein gene $(C D 2 A P)$ encodes a scaffolding protein that binds directly to actin [41], nephrin and other proteins involved in cytoskeletal organization. In the immune system, CD2AP is required for synapse formation [42] in a process that involves clathrin-dependent actin polymerization. $A B C A 7$ is an integral transmembrane ATP-binding cassette transporter belonging to the $\mathrm{ABC}$ family proteins that mediate the biogenesis of high-density lipoprotein with cellular lipid and helical apolipoproteins [43]. It binds APOA-I and functions in apolipoprotein-mediated phospholipid and cholesterol efflux from cells [44]. However, ABCA7also affects the transport of other important proteins, including APP, [44] through the cell membrane and is involved in host defense through effects on phagocytosis by macrophages of apoptotic cells [43].

In the largest GWAS performed to date in Caribbean Hispanics [45] associations in CLU,PICALM, and BIN1 were replicated and several additional loci on 2p25.1, 3q25.2, 7p21.1 and 10q23.1 - which could be replicated in an independent cohort of non-Hispanic Whites of European ancestry from the National Institute on Aging Late-Onset Alzheimer's Disease Family Study (NIA-LOAD) were observed. In the largest GWAS of African Americans performed to date, Reitz et al. [46] identified $A B C A 7$ as a major susceptibility locus in this ethnic group and replicated $C R 1$. 
Based on genotyping chip and quality control design, GWAS by definition capture mostly common genetic variation with small to moderate effect sizes. In line with this notion, all abovementioned ADassociated variants outside the $A P O E$ locus that have been identified by GWAS are common and have small effect sizes $(1.0<\mathrm{OR}<1.2)$ leaving a large part of the genetic contribution to the disease unexplained. It is likely that much of the 'missing heritability' is explained by rare genetic variants with a minor allele frequency (MAF) below 1\% [47]which are commonly excluded from GWAS. Moreover, imputation, which is used to infer non genotyped variants, often fails to show acceptable accuracy at low MAF (i.e. MAF<0.3) [48].

In line with this notion, two recent studies that performed genome sequencing followed by imputation of identified variants in independent datasets implicated the triggering receptor expressed on myeloid cells 2 (TREM2) gene in AD by identifying a causative rare missense mutation (rs75932628) which results in an $\mathrm{R} 47 \mathrm{H}$ substitution and confers a threefold increase in risk. The TREM2 gene istranslated into a type-I membrane protein with an extracellular Iglike domain and was first described as potentially involved in chronic inflammation response [49]. TREM2 is widely expressed in the brain, on myeloid and natural killer cells, some T and B cells and osteoclasts. Its signaling capacity is carried out through coupling with DAP12, a cytosolic adapter with dual function (activation and inhibition of several immune cell types)resulting in cytokine production regulation [50]. This regulatory effect is thought to be fundamental for regulating microglia activity which in turn enhances development ofamyloid plaques, the key pathological hallmark in $\mathrm{AD}$ [51]. Of note, a loss of function of TREM2 had been previously described to be associated with an autosomal recessive form of early-onset dementia presenting with bone cysts and quasi-spontaneous fractures called "polycystic lipomembranous osteodysplasia with sclerosing leukoencephalopathy" or "Nasu-Hakola disease" [52]. Other homozygous TREM2 mutations have been described in patients presenting with frontotemporal-like dementia [53]. Besides implicating this gene in the disease, these two studies provided significant confirmation that not only common but also rare variants are involved in late-onset AD.

\section{Conclusions and Future Perspective}

The genetic studies from the past decade have added a significant body of evidence for a causative involvement of inflammation and the immune system in $\mathrm{AD}$ etiology through identification of several disease-associated genes functioning in this pathway. The recent advances in next generation whole exome (WES) and whole genome sequencing (WGS) will help to identify specific disease-associated alleles in these genes. In addition, it is likely that, besides identifying additional genes that are part of other pathways involved including lipid metabolism, intracellular trafficking and APP metabolism, they will identify further common and rare variants in inflammation- and immune response-related genes that will explainpart of the heritability still missing.

It is important to note that before the known information on genes involved is used in clinical settings several additional issues have to be clarified. First, it has to be clarified at what stage of the AD disease process the inflammation-related risk genes might exert its effect. Recent high throughput transcriptome studies based on hippocampal neurons indicate an early-stage involvement of inflammatory regulators [54]. Second, more functional validation of these genes is needed. Before any of the identified genes can be safely used as a target for prevention, treatment or diagnostic testing, it has to be fully clarified through which mechanisms theyexert their effects on AD risk, in which other pathways they are involved and interact with, and which effects a modulation of their function would have.

\section{Acknowledgements}

Dr. Reitz was supported by a Paul B. Beeson Career Development Award (K23AG034550). Dr. Tosto was supported by Whole Exome Analysis of Early Onset Alzheimer's Disease Grant (W81XWH)

\section{References}

1. Eikelenboom $\mathrm{P}$, Veerhuis $\mathrm{R}$ (1996) The role of complement and activated microglia in the pathogenesis of Alzheimer's disease. Neurobiol Aging 17: 673680

2. R Rogers J, Schultz J, Brachova L, Lue LF, Webster S, et al. (1992) Complement activation and beta-amyloid-mediated neurotoxicity in Alzheimer's disease. Res Immunol 143: 624-630.

3. Rozemuller JM, Eikelenboom P, Stam FC, Beyreuther K, Masters CL (1989) A4 protein in Alzheimer's disease: primary and secondary cellular events in extracellular amyloid deposition. J Neuropathol Exp Neurol 48: 674-691.

4. Yan SD, Stern D, Kane MD, Kuo YM, Lampert HC, et al. (1998) RAGE-Abeta interactions in the pathophysiology of Alzheimer's disease. Restor Neurol Neurosci 12: 167-173.

5. Paresce DM, Ghosh RN, Maxfield FR (1996) Microglial cells internalize aggregates of the Alzheimer's disease amyloid beta-protein via a scavenger receptor. Neuron 17: 553-565.

6. Fassbender K, Walter S, Kühl S, Landmann R, Ishii K, et al. (2004) The LPS receptor (CD14) links innate immunity with Alzheimer's disease. FASEB J 18 203-205.

7. Bate C, Veerhuis R, Eikelenboom P, Williams A (2004) Microglia kill amyloidbeta1-42 damaged neurons by a CD14-dependent process. Neuroreport 15 1427-1430.

8. Jana M, Palencia CA, Pahan K (2008) Fibrillar amyloid-beta peptides activate microglia via TLR2: implications for Alzheimer's disease. J Immunol 181: 7254 7262.

9. Stewart CR, Stuart LM, Wilkinson K, van Gils JM, Deng J, et al. (2010) CD36 ligands promote sterile inflammation through assembly of a Toll-like receptor 4 and 6 heterodimer. Nat Immunol 11: 155-161.

10. Heneka MT, O'Banion MK, Terwel D, Kummer MP (2010) Neuroinflammatory processes in Alzheimer's disease. J Neural Transm117: 919-947.

11. Kitazawa M, Oddo S, Yamasaki TR, Green KN, LaFerla FM (2005) Lipopolysaccharide-induced inflammation exacerbates tau pathology by a cyclin-dependent kinase 5-mediated pathway in a transgenic model of Alzheimer's disease. J Neurosci 25: 8843-8853.

12. Ard MD, Cole GM, Wei J, Mehrle AP, Fratkin JD (1996) Scavenging of Alzheimer's amyloid beta-protein by microglia in culture. J Neurosci Res 43 : 190-202.

13. Akiyama H, Schwab C, Kondo H, Mori H, Kametani F, et al. (1996) Granules in glial cells of patients with Alzheimer's disease are immunopositive for C-terminal sequences of beta-amyloid protein. Neurosci Lett 206: 169-172.

14. Herber DL, Roth LM, Wilson D, Wilson N, Mason JE, et al. (2004) Timedependent reduction in Abeta levels after intracranial LPS administration in APP transgenic mice. Exp Neurol 190: 245-253.

15. El Khoury J, Toft M, Hickman SE, Means TK, Terada K, et al. (2007) Ccr2 deficiency impairs microglial accumulation and accelerates progression of Alzheimer-like disease. Nat Med13: 432-438.

16. Wyss-Coray T, Yan F, Lin AH, Lambris JD, Alexander JJ, et al. (2002) Prominent neurodegeneration and increased plaque formation in complementinhibited Alzheimer's mice. Proc Natl Acad Sci U S A 99: 10837-10842.

17. Sheng JG, Bora SH, Xu G, Borchelt DR, Price DL, et al. (2003) Lipopolysaccharide-induced-neuroinflammation increases intracellular accumulation of amyloid precursor protein and amyloid beta peptide in APPswe transgenic mice. Neurobiol Dis 14: 133-145.

18. Hoozemans JJ, Veerhuis R, Rozemuller JM, Eikelenboom P (2006) Neuroinflammation and regeneration in the early stages of Alzheimer's disease pathology. Int J Dev Neurosci 24: 157-165. 
Citation: Reitz C, Tosto G (2013) Inflammation, Immune System and Alzheimer's disease: A Review of the Findings from the Major GWAS Studies. J Mol Genet Med 7: 60. doi:10.4172/1747-0862.1000060

19. Cagnin A, Brooks DJ, Kennedy AM, Gunn RN, Myers R, et al. (2001) In-vivo measurement of activated microglia in dementia. Lancet 358: 461-467.

20. Okello A, Edison P, Archer HA, Turkheimer FE, Kennedy J, et al. (2009) Microglial activation and amyloid deposition in mild cognitive impairment: a PET study. Neurology 72: 56-62.

21. Alkalay A, Rabinovici GD, Zimmerman G, Agarwal N, Kaufer D, et al. (2013) Plasma acetylcholinesterase activity correlates with intracerebral beta-amyloid load. Curr Alzheimer Res 10: 48-56.

22. Wyss-Coray T, Rogers $\mathrm{J}$ (2012) Inflammation in Alzheimer disease-a brie review of the basic science and clinical literature. Cold Spring Harb Perspect Med.

23. Osera C, Pascale A, Amadio M, Venturini L, Govoni S, et al. (2012) Pentraxins and Alzheimer's disease: at the interface between biomarkers and pharmacological targets. Ageing Res Rev 11: 189-198.

24. Harold D, Abraham R, Hollingworth P, Sims R, Gerrish A, et al. (2009) Genomewide association study identifies variants at CLU and PICALM associated with Alzheimer's disease. Nat Genet 41: 1088-1093.

25. Lambert JC, Heath S, Even G, Campion D, Sleegers K, et al. (2009) Genomewide association study identifies variants at CLU and CR1 associated with Alzheimer's disease. Nat Genet 41: 1094-1099.

26. Seshadri S, Fitzpatrick AL, Ikram MA, DeStefano AL, Gudnason V, et al. (2010) Genome-wide analysis of genetic loci associated with Alzheimer disease. Jama 303: $1832-1840$

27. Wollmer MA, Sleegers K, Ingelsson M, Zekanowski C, Brouwers N, et al. (2007) Association study of cholesterol-related genes in Alzheimer's disease. Neurogenetics 8: 179-88.

28. Nuutinen T, Suuronen T, Kauppinen A, Salminen A (2009) Clusterin: a forgotten player in Alzheimer's disease. Brain Res Rev 61: 89-104.

29. DeMattos RB, Cirrito JR, Parsadanian M, May PC, O'Dell MA, et al. (2004) ApoE and clusterin cooperatively suppress Abeta levels and deposition: evidence that $A p o E$ regulates extracellular Abeta metabolism in vivo. Neuron 41: 193-202.

30. Tebar F, Bohlander SK, Sorkin A (1999) Clathrin assembly lymphoid myeloid leukemia (CALM) protein: localization in endocytic-coated pits, interactions with clathrin, and the impact of overexpression on clathrin-mediated traffic. Mol Biol Cell 10: 2687-2702.

31. Crehan H, Holton P, Wray S, Pocock J, Guerreiro R, et al. (2012) Complemen receptor 1 (CR1) and Alzheimer's disease. Immunobiology 217: 244-250.

32. McGeer PL, Rogers J (1992) Anti-inflammatory agents as a therapeutic approach to Alzheimer's disease. Neurology 42: 447-449.

33. Cao H, Crocker PR (2011) Evolution of CD33-related siglecs: regulating host immune functions and escaping pathogen exploitation? Immunology 132: 1826.

34. von Gunten S, Bochner BS (2008) Basic and clinical immunology of Siglecs. Ann N Y Acad Sci 1143: 61-82.

35. Vitale C, Romagnani C, Falco M, Ponte M, Vitale M, et al. (1999) Engagement of p75/AIRM1 or CD33 inhibits the proliferation of normal or leukemic myeloid cells. Proc Natl Acad Sci U S A 96: 15091-15096.

36. Yamazaki T, Masuda J, Omori T, Usui R, Akiyama H, et al. (2009) EphA1 interacts with integrin-linked kinase and regulates cell morphology and motility. J Cell Sci 122: 243-255.

37. Adams RH, Klein R (2000)Eph receptors and ephrin ligands. essential mediators of vascular development. Trends Cardiovasc Med 10: 183-188.

38. Duffy SL, Coulthard MG, Spanevello MD, Herath NI, Yeadon TM, et al. (2008) Generation and characterization of EphA1 receptor tyrosine kinase reporter knockout mice. Genesis 46: 553-561.

39. Holen HL, Nustad K, Aasheim HC (2010) Activation of EphA receptors on CD4+CD45RO+ memory cells stimulates migration. J Leukoc Biol 87: 10591068.
40. Sakamoto A, Sugamoto Y, Tokunaga Y, Yoshimuta T, Hayashi K, et al. (2011) Expression profiling of the ephrin (EFN) and Eph receptor (EPH) family of genes in atherosclerosis-related human cells. J Int Med Res 39: 522-527.

41. Lehtonen S, Zhao F, Lehtonen E (2002) CD2-associated protein directly interacts with the actin cytoskeleton. Am J Physiol Renal Physiol 283: F734743

42. Dustin ML, Olszowy MW, Holdorf AD, Li J, Bromley S, et al. (1998) A novel adaptor protein orchestrates receptor patterning and cytoskeletal polarity in T-cell contacts. Cell 94: 667-677.

43. Tanaka N, Abe-Dohmae S, Iwamoto N, Yokoyama S (2011) Roles of ATPbinding cassette transporter A7 in cholesterol homeostasis and host defense system. J Atheroscler Thromb 18: 274-281.

44. Chan SL, Kim WS, Kwok JB, Hill AF, Cappai R, et al. (2008) ATP-binding cassette transporter $A 7$ regulates processing of amyloid precursor protein in vitro. J Neurochem 106: 793-804.

45. Lee JH, Cheng R, Barral S, Reitz C, Medrano M, et al. (2011) Identification of novel loci for Alzheimer disease and replication of CLU, PICALM, and BIN1 in Caribbean Hispanic individuals. Arch Neurol 68: 320-328.

46. Reitz C, Jun G, Naj A, Rajbhandary R, Vardarajan BN, et al. (2013) Variants in the ATP-binding cassette transporter (ABCA7), apolipoprotein $E$, and the risk of late-onset Alzheimer disease in African Americans. Jama 309: 1483-1492.

47. Bansal V, Libiger O, Torkamani A, Schork NJ (2010) Statistical analysis strategies for association studies involving rare variants. Nat Rev Genet 11: 773-785.

48. Zheng HF, Ladouceur M, Greenwood CM, Richards JB, et al. (2012) Effect of genome-wide genotyping and reference panels on rare variants imputation. J Genet Genomics 39: 545-550.

49. Bouchon A, Dietrich J, Colonna M (2000) Cutting edge: inflammatory responses can be triggered by TREM-1, a novel receptor expressed on neutrophils and monocytes. J Immunol 164: 4991-4995.

50. Takaki R, Watson SR, Lanier LL (2006) DAP12: an adapter protein with dua functionality. Immunol Rev 214: 118-129.

51. Braak H, Braak E (1996) Evolution of the neuropathology of Alzheimer's disease. Acta Neurol Scand Suppl 165: 3-12.

52. Verloes A, Maquet $P$, Sadzot B, Vivario M, Thiry A, et al., (1997) NasuHakola syndrome: polycystic lipomembranous osteodysplasia with sclerosing leucoencephalopathy and presenile dementia. J Med Genet 34: 753-757.

53. Guerreiro RJ, Lohmann E, Brás JM, Gibbs JR, Rohrer JD, et al. (2012) USing exome sequencing to reveal mutations in trem2 presenting as a frontotempora dementia-like syndrome without bone involvement. JAMA Neurol 7: 78-84.

54. Barbash S, Soreq H (2012) Threshold-independent meta-analysis of Alzheimer's disease transcriptomes shows progressive changes in hippocampal functions epigenetics and microRNA regulation. Curr Alzheimer Res 9: 425-435. 